\title{
Dental bleaching agents with calcium and their effects on enamel microhardness and morphology
}

\author{
Andréia Mara Andrade Pizani ${ }^{1}$, Beatriz Tholt ${ }^{2}$, Sidnei Paciornik ${ }^{3}$, Katia Regina Hostilio Cervantes Dias ${ }^{4}$, \\ Pedro Paulo Albuquerque Cavacanti de Albuquerque ${ }^{5}$, Celso Silva Queiroz ${ }^{2}$
}

\begin{abstract}
${ }^{1}$ Universidade Paulista - UNIP, School of Dentistry, Department of Restorative Dentistry, São Paulo, SP, Brazil
2Universidade Veiga de Almeida - UVA, School of Dentistry, Department of Restorative Dentistry, Rio de Janeiro, RJ, Brazi ${ }^{3}$ Pontifícia Universidade Católica do Rio de Janeiro - PUC-Rio, School of Materials Engineering, Department of Materials Engineering - DEMa, Rio de Janeiro, RJ, Brazil ${ }^{4}$ Universidade Federal do Rio de Janeiro - UFRJ, School of Dentistry, Department of Restorative Dentistry, Rio de Janeiro, RJ, Brazil

${ }^{5}$ Universidade de São Paulo - USP, School of Dentistry, Departament of Biomaterials and Oral Biology, São Paulo, SP, Brazil
\end{abstract}

\begin{abstract}
Aim: To evaluate enamel microhardness and morphology after bleaching with hydrogen peroxide containing calcium in different concentrations. Methods: One hundred specimens of human teeth were ground and polished and had the initial microhardness evaluated. The specimens were randomly assigned into five groups ( $\mathrm{n}=20)$ : Group 1 - Control group (no treatment); Group 2 - Home Peroxide 6\% (without calcium); Group 3 - Home Peroxide 7.5\% (without calcium); Group 4 - White Class 6\% (with calcium); Group 5 - White Class 7.5\% (with calcium). For each group, the bleaching was performed according to the manufacturer's specifications. The specimens were bleached once a day for 5 days and subjected to $\mathrm{pH}$ cycling. Microhardness and scanning electron microscopy (SEM) analysis were performed before and after bleaching. Results: The results showed that groups submitted to bleaching treatment presented hardness loss compared to the control group. The group of $7.5 \%$ hydrogen peroxide with calcium showed a lower percentage of hardness loss in relation to other groups. Conclusion: Calcium in association with a higher hydrogen peroxide concentration may decrease microhardness changes on enamel.
\end{abstract}

Keywords: bleaching agents; calcium; hydrogen peroxide; dental enamel.

\section{Introduction}

Several techniques have been used to promote teeth whitening, including home bleaching technique and the one performed at the office. There are commercially available gels in different chemical formulations and concentrations,

Received for publication: December 18, 2014 Accepted: June 20, 2015

Correspondence to: Celso Silva Queiroz Universidade Veiga de Almeida - UVA Rua Ibituruna, 108, Tijuca,

CEP: 20271-021 Rio de Janeiro, RJ Phone: +55 2125748871

E-mail: celsoq@yahoo.com including carbamide peroxide (CP) from $10 \%$ to $37 \%$ and hydrogen peroxide (HP) from $6 \%$ to $38 \%$. Dental enamel is composed of a huge number of highly mineralized prisms, and its hardness is due to a high percentage of inorganic matrix (95\%) made of hydroxyapatite crystals (calcium phosphate) and low percentage of organic protein nature matrix $(0.36$ to $2 \%)$ together with polysaccharides ${ }^{1}$. The enamel permeability is low, but it acts as a semipermeable membrane allowing the diffusion of water and some ions.

Teeth whitening usually generates concern about the possibility of enamel 
chemical changes, especially when peroxides with great diffusivity are applied in high concentrations ${ }^{2-3}$. Some bleaching gels are presented in low $\mathrm{pH}$ solutions to ensure the stability of hydrogen peroxide, so these bleaching solutions with acidic $\mathrm{pH}$, may promote microstructure and chemical changes in the enamel ${ }^{3}$. Changes in chemical composition of enamel may reflect on modified values of mechanical properties, resulting in undesirable effects such as reduction in hardness and/or flexural strength ${ }^{4}$. On the other hand, different authors stated that bleaching is effective and unable to cause deleterious effects on the enamel surface ${ }^{5-}$ 7. Thus, regardless of the aesthetic results achieved by different whitening techniques, the effects of bleaching agents on enamel are yet not completely understood.

Assuming that enamel is mainly composed by calcium, phosphorus, oxygen and carbon $\mathrm{Ca}_{10}\left(\mathrm{PO}_{4}\right)_{6}(\mathrm{OH})_{2}$, in vitro assays designed to identify these components are desirable to reveal possible alterations of enamel's chemical structure. Some studies showed that dental bleaching alters the enamel chemically and have shown decreased calcium values in enamel ${ }^{5-6,8}$.

In order to minimize such demineralization after contact with bleaching agents, some biomaterials such as fluoride, hydroxyapatite, calcium ions and amorphous calcium have been added to the composition of those whitening agents? Beneficial effects of combining these substances with bleaching agents have been verified in previous studies ${ }^{3,9-10}$, which concluded that such association may protect the enamel from demineralization and also may avoid hypersensitivity during the procedure. However, fluoride and calcium addition to the bleaching agents were not sufficient to increase the microhardness of enamel ${ }^{11}$.

Thus, the aim of this study was to evaluate the microhardness of enamel after bleaching with hydrogen peroxide $6 \%$ and $7.5 \%$, with or without calcium. Additionally, scanning electron microscopy (SEM) was employed to analyze the structure of the enamel surface before and after application of peroxides.

\section{Material and methods}

One hundred human permanent molars, obtained from the local Tooth Bank, were used after approval by the Ethics Committee in Research (protocol number 705/09).

The crowns were separated from roots and an enamel block $(3 \times 3 \times 2 \mathrm{~mm})$ was removed from the buccal surface of the crowns. The specimens (enamel blocks) were ground wet in a mechanical grinding machine with aluminum oxide discs of sequentially decreasing granulation and polished with diamond pastes and felt discs under mineral oil cooling.

The specimens were identified and remained stored in humidified atmosphere at $37{ }^{\circ} \mathrm{C}$ during the experiment.

Surface microhardness was assessed before the bleaching and $\mathrm{pH}$ cycling procedures. The measurements were performed in 3,500 blocks using a microhardness tester (Future Tech FM - 300; Shimadzu, Tokyo, Japan) with a Knoop indenter (25 g/ $5 \mathrm{~s})$. Three lines with five indentations each were made on the enamel surface at a distance of $100 \mu \mathrm{m}$, resulting in fifteen indentations. After obtaining the initial microhardness, one hundred blocks were selected $(153 \pm 10 \mathrm{KHN}$ - baseline $)$ and randomly divided into five groups $(n=20)$ in according to the bleaching treatment. The control group was subjected to $\mathrm{pH}$ cycling, but not to bleaching (Table 1). The basic composition of bleaching agents is shown in Table 1.

The specimens were submitted to $\mathrm{pH}$ cycling for 5 days at $37{ }^{\circ} \mathrm{C}$, in order to simulate the effects of demineralization and re-mineralization that occur in the oral cavity. The specimens were immersed in a demineralizing solution $(2.0$ $\mathrm{mM} \mathrm{Ca}$ and $\mathrm{P}$ in $0.075 \mathrm{M}$ acetate buffer, $\mathrm{pH} 4.3-6.25 \mathrm{~mL} /$ $\mathrm{mm}^{2}$ ) for $6 \mathrm{~h}$ and immersed in remineralizing solution $(1.5$ $\mathrm{mM}$ and $0.9 \mathrm{mM} \mathrm{P}$ in $0.1 \mathrm{M}$ tris buffer, $\mathrm{pH}$ 7.0) for $17 \mathrm{~h}^{12}$

The specimens had the bleaching agent applied for $1 \mathrm{~h}$, between the demineralizing and remineralizing solutions, once daily for five days. Bleaching technique was carried out according to the manufacturer's specifications after prophylaxis with pumice stone and water. A calibrated syringe was used to place $0.02 \mathrm{~mL}$ of each bleaching agent on the specimen. The bleaching agents were removed from the dental specimens with distilled deionized water, causing no changes on the enamel surface.

After pH cycling, surface microhardness was again assessed on each specimen as previously mentioned. Five specimens from each group were randomly chosen and analyzed by SEM (SSX - 550, Shimadzu) and just one unbleached specimen served as control group. The specimens were dried, fixed on aluminum stubs and sputter-coated with gold. The surface morphology of enamel was qualitatively examined at $5000 \mathrm{x}$ magnification.

Statistical analysis was carried out by ANOVA in a split plot randomized design, considering the bleaching product (gel) factor. The Tukey's test was used for comparison with a 5\%

Table 1. Basic composition and manufacturer of each bleaching agent.

\begin{tabular}{|c|c|c|}
\hline Groups & Calcium & Composition \\
\hline \multicolumn{3}{|l|}{1 - Control* } \\
\hline 2 - Home Peroxide 6\% - DMC ${ }^{\circledR}$ & No & $\begin{array}{l}\text { Hydrogen peroxide, sodium fluoride, potassium nitrate, water, carbomer, amine, } \\
\text { preservative,flavorizer. }\end{array}$ \\
\hline 3 - Home Peroxide 7.5\% - DMC ${ }^{\circledR}$ & No & $\begin{array}{l}\text { Hydrogen peroxide, sodium fluoride, potassium nitrate, water, carbomer, amina, } \\
\text { preservative,Flavorizer. }\end{array}$ \\
\hline 4 - White Class 6\% - FGM ${ }^{\circledR}$ & Yes & Hydrogen peroxide, sodium fluoride, potassium nitrate, water, Aloe vera, calcium. \\
\hline 5 - White Class $7.5 \%$ - $\mathrm{FGM}^{\circledR}$ & Yes & Hydrogen peroxide, sodium fluoride, potassium nitrate, water, Aloe vera, calcium. \\
\hline
\end{tabular}

* Control group - no bleaching treatment and subjected to $\mathrm{pH}$ cycling.

The manufacturers do not provide all components of the formulations. 
Table 2. Initial and final microhardness means and standard deviations and percentage loss of surface microhardness (\%SML) in experimental groups

\begin{tabular}{lccc}
\hline Groups & Initial & Final $^{*}$ & $\%$ SML \\
1-Control & $337.45 \pm 17.37$ & $221.90 \pm 16.34 \mathrm{a}$ & -34.72 \\
2-Home Peroxide 6.0\% (without calcium) & $281.43 \pm 21.57$ & $87.54 \pm 3.07 \mathrm{~b}$ & -59.61 \\
3- Home Peroxide 7.5\% (without calcium) & $309.89 \pm 13.70$ & $85.09 \pm 2.78 \mathrm{~b}$ & -71.23 \\
4-White Class 6.0\% (with calcium) & $307.96 \pm 25.79$ & $95.97 \pm 3.63 \mathrm{~b}$ & -64.05 \\
5- White Class 7.5\% (with calcium) & $272.31 \pm 18.20$ & $110.95 \pm 7.43 \mathrm{c}$ & -53.43 \\
\hline
\end{tabular}

${ }^{*}$ Mean values with different letters differ statistically from each other $(p<0.05)$.

confidence level $(\alpha=0.05)$. The percentage of hardness reduction (mean) was assessed by the microhardness values. The statistical program was SAS 7.0 (SAS Institute, Cary, NC, USA).

\section{Results}

Groups treated with bleaching gels showed a statistically significant hardness loss compared to the control group (Table 2). Comparison of groups treated with Home Peroxide without calcium at $6.0 \%$ and $7.5 \%$, showed no statistically significant differences (Table 2). Groups treated with Home Peroxide with calcium at 6.0 and $7.5 \%$, showed different values $(p<0.05)$. However, only the $7.5 \%$ group with calcium was statistically different $(\mathrm{p}<0.05)$ from the others (Table $2)$. The control group lost $35 \%$ of the enamel hardness; the groups without calcium at $6.0 \%$ and $7.5 \%$ lost $60 \%$ and $71 \%$ respectively. Groups with calcium at $6.0 \%$ and $7.5 \%$ lost $64 \%$ and $53 \%$ respectively (Table 2).

The SEM images revealed changes in the enamel structure as result of bleaching with Home Peroxide and White Class with or without calcium (Figures $1-5$ ).

\section{Discussion}

Bleaching agents are primarily made of hydrogen peroxide and are classified by the U.S. Food and Drug Administration - FDA - as Class I agents, i.e., products generally recognized as safe and effective. However, their

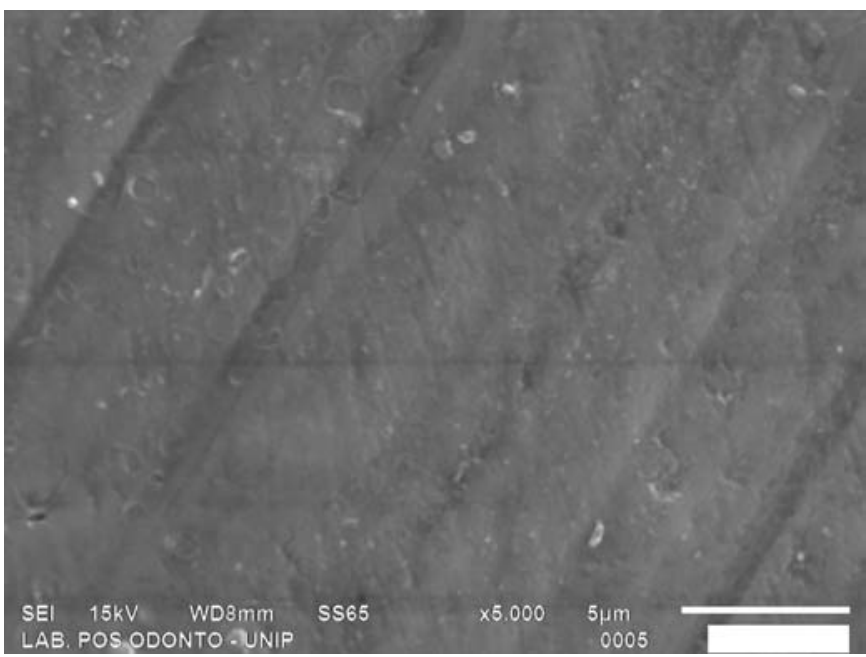

Fig. 1. Control Group - No bleaching treatment.

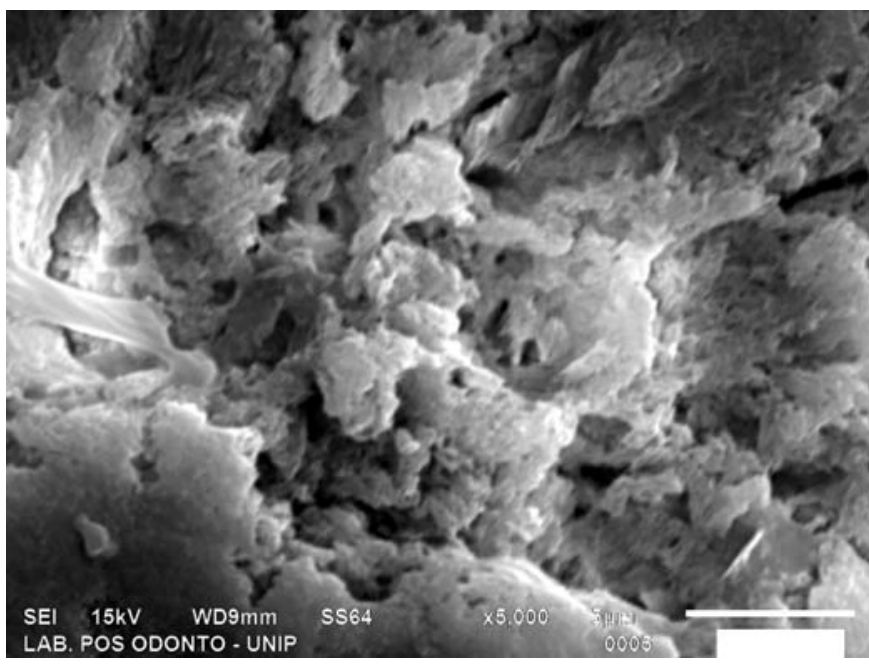

Fig. 2. Home peroxide $6.0 \%$ - without calcium.

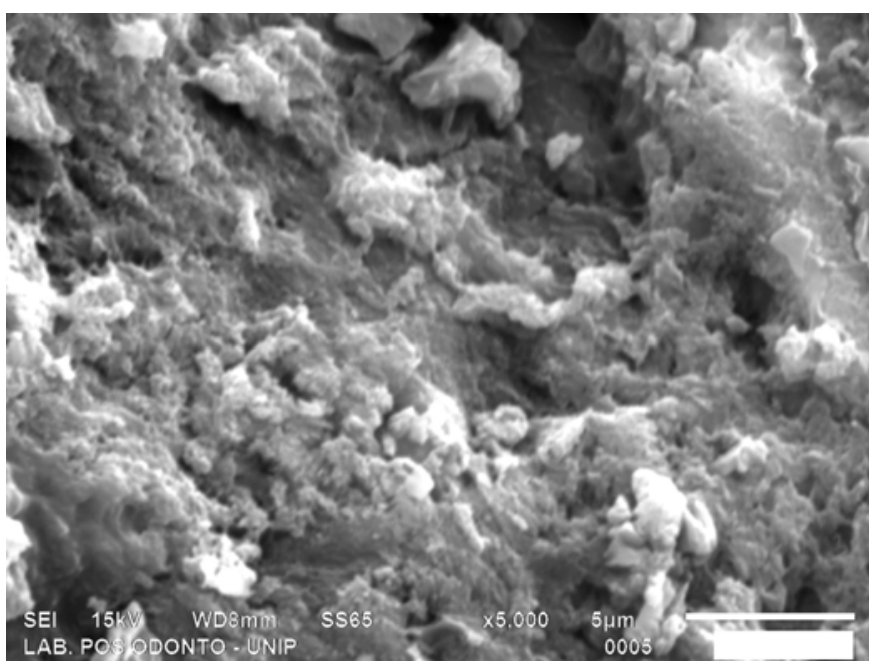

Fig. 3. Home peroxide $7.5 \%$ - without calcium.

indiscriminate use, especially at higher concentrations, led the scientific council of the American Dental Association to establish criteria for bleaching agents' approval, since it should have neutral $\mathrm{pH}$, its formula must be specified because of each ingredient function, the action mechanism of active agents and user's instructions.

Oxidation-reduction reaction of bleaching agents produce hydrogen ions $\left(\mathrm{H}^{+}\right)$that can create an acidic environment and lead to dissolution of the organic and inorganic enamel ${ }^{13-14}$. The action of acid on the enamel 


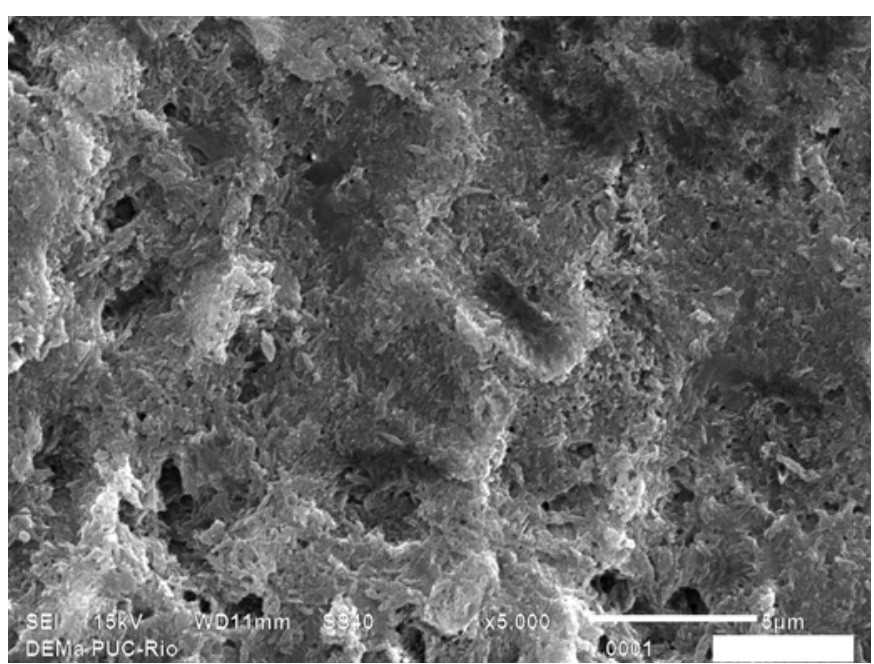

Fig. 4. White class $6.0 \%$ - with calcium.

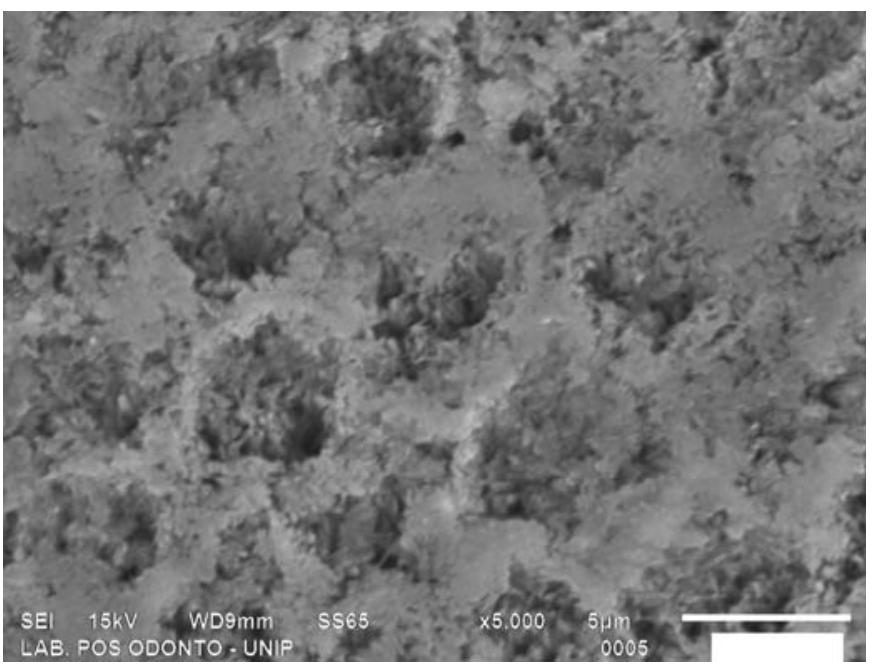

Fig. 5. White class 7.5\% - with calcium.

structure may result in erosion that reduces its translucency, promoting opacity, which is a common effect in bleaching treatments ${ }^{5}$. However, whether this erosion is caused directly by the bleaching agent's $\mathrm{pH}$, is still controversial.

Enamel re-mineralization is expected due to the action of saliva, especially in the case of agents used in this study, with concentrations advised for home technique, which usually lasts between 14 and 30 days. In this technique, the tooth enamel in contact with the whitening gel is subject to the action of the demineralization and re-mineralization processes in the oral environment, factors that can greatly affect the results of erosion on dental enamel ${ }^{3}$. The $\mathrm{pH}$ changes that occur in the mouth may interfere with the action of bleaching agents, thus the $\mathrm{pH}$ cycling was performed in this study in an attempt to simulate the clinical condition ${ }^{15}$.

Several studies have shown enamel microhardness loss after the use of bleaching agents ${ }^{16}$. Thus, a microhardness test is often used for in vitro studies to evaluate possible deleterious effects of tooth whitening ${ }^{17}$.The results of this study showed that treatment with hydrogen peroxide gels may decrease the microhardness values, which was observed in previous findings ${ }^{17-20}$. The control group showed a decrease of $34.7 \%$ between the initial and final microhardness values. This change was also demonstrated in another study ${ }^{20}$. Although the demineralizing (De) and remineralizing ( $\mathrm{Re}$ ) solutions were buffered to regular $\mathrm{pH}$, it is believed that washing with distilled water and the six hours' time of the De solution, exceeds the mineral replacement action of the mineral Re solution.

In order to minimize the enamel mineral loss during tooth whitening, introduction of calcium in its composition was proposed ${ }^{21-22}$. According to our results, $7.5 \%$ hydrogen peroxide-based whitening gel with calcium showed the smallest microhardness decrease $(p<0.05)$, while the whitening gel at $6,0 \%$ with calcium showed the same behavior as the one without calcium. The concentration of hydrogen peroxide $(7.5 \%)$ may lead to greater enamel demineralization and promote ionic imbalance, so the calcium contained in the composition of the bleaching agent may be more effective incorporating into the enamel surface. Some studies pointed out that different bleaching agents have reduced the enamel microhardness values, although these values were recovered after treatment by contact with saliva ${ }^{19}$.

An ideal system of remineralization should provide not only calcium ions, but also phosphorus and fluoride ions, since they are also lost by ename ${ }^{11}$. The amorphous calcium phosphate (ACP) is a remineralizing substance and when stabilized by casein phosphopeptide (CPP), its remineralizing potential is higher (calcium, phosphorus and fluoride ions) compared with the ACP and sodium fluoride ${ }^{23}$. The same authors also related the positive effects of ACP incorporation as more important to low concentrations of hydrogen peroxide in combination with saliva. For this reason, the authors believe that incorporating one or more biomaterials such as calcium, hydroxyapatite or fluoride in the bleaching agents composition is quite promising. The present study showed that a higher concentration of hydrogen peroxide $(7.5 \%)$ with calcium was more effective; however, comparison must be viewed with caution, because the authors used amorphous calcium in saliva and not calcium ions in artificial saliva.

The SEM analysis revealed structural changes on the enamel surface after bleaching agent application. The images corresponding to the experimental groups show erosions and discontinuities on enamel surface compared to the control group. Others authors identified craters, depression areas, erosion, aprismatic layer removal and exposure of the enamel rods $^{24}$. This may be explained by the radicals stemming from oxidizing agents, i.e., diffusion of them at about 100 ìm on the enamel surface ${ }^{23}$. Thus, according to our results it may be suggested that the enamel's external surface is more susceptible to bleaching.

According to the results and inherent limitations of this research, further studies should be carried out to minimize the change in enamel mechanical and structural properties when subjected to bleaching agents, either by incorporating remineralizing components, or using them in association with the whitening techniques. All bleaching gels cause loss of hardness on human dental enamel. However, the inhibition 
of enamel demineralization may be related not only to the presence of calcium, but to the concentration of bleaching gel.

\section{Acknowledgements}

The authors wish to thank the Postgraduate Laboratory of Paulista University (UNIP) and the laboratory technician Mr. Felipe Barros for his assistance. Thanks also to Mr. Vitor Brandão and Professor Marcos Henrique Pinho Maurício (DEMA-PUC) for helping with the laboratory procedures and sharing their expertise.

\section{References}

1. Özcan M, Dündar M, Çömlekoðlu E. Adhesion concepts in dentistry: tooth and material aspects. J Adhes Sci Technol. 2012; 26: 2661-81.

2. Cakir FY, Korkmaz Y, Oztas EFSS, Gurgan S. Chemical analysis of enamel and dentin following the application of three different at-home bleaching systems. Oper Dent. 2011; 36: 529-36.

3. Xu B, Li Q, Wang Y. Effects of $\mathrm{pH}$ values of hydrogen peroxide bleaching agents on enamel surface properties. Oper Dent. 2011; 36: 554-62.

4. Khoroushi M, Mazaheri H, ManoochehriA. Effect of CCP-ACP application on flexural strength of bleached enamel and dentin complex. Oper Dent. 2011; 36: 372-9.

5. 5.. Soares DG, Basso FG, Pontes ECV, Garcia LFR, Hebling J, de Souza Costa CA. Effective tooth-bleaching protocols capable of reducing $\mathrm{H} 2 \mathrm{O} 2$ diffusion through enamel and dentine. J Dent. 2014; 42: 351-8.

6. Tamam E, Aydin K, Bilgiç S. Electrochemical corrosion and surface analyses of a Ni-Cr alloy in bleaching agents. J Prosthodont. 2014; 23: 549-58.

7. Sasaki RT, Arcanjo AJ, Flório FM, Basting RT. Micromorphology and microhardness of enamel after treatment with home-use bleaching agents containing $10 \%$ carbamide peroxide and $7.5 \%$ hydrogen peroxide. J Appl Oral Sci. 2009; 17: 611-6.

8. Pedreira de Freitas AC, Botta SB, Teixeira F de S, Salvadori MC, Garone-Netto N. Effects of fluoride or nanohydroxiapatite on roughness and gloss of bleached teeth. Microsc Res Tech. 2011; 74: 1069-75.

9. Jin J, Xu X, Lai G, Kunzelmann KH. Efficacy of tooth whitening with different calcium phosphate-based formulations. Eur J Oral Sci 2013; 121: 382-8.

10. De Abreu DR, Sasaki RT, Amaral FLB, Flório FM, Basting RT. Effect of home-use and in-office bleaching agents containing hydrogen peroxide associated with amorphous calcium phosphate on enamel microhardness and surface roughness. J EsthetRestor Dent. 2011; 23: 158-68.

11. Kim YS, Kwon HK, Kim BI. Effect of nano-carbonate apatite to prevent restain after dental bleaching in vitro. J Dent. 2011; 39: 636-42.

12. Queiroz, CS, Hara AT, Paes Leme AF, Cury JA. pH-cycling models to evaluate the effect of low fluoride dentifrice on enamel de- and remineralization. Braz Dent J. 2008; 19: 21-7.

13. Oskoee PA, Navimipour EJ, Oskoee SS, Moosavi N. Effect of $10 \%$ sodium ascorbate on bleached bovine enamel surface morphology and microhardness. Open Dent J. 2010 21: 207-10.

14. Sulieman $M$, Addy $M$, MacDonald $E$, Rees JS. A safety study in vitro for the effects of an in-office bleaching system on the integrity of enamel and dentine. J Dent. 2004; 32: 581-90.

15. Mahmoud S, Elembaby A, Zaher A, Grawish M, Elsabaa H, El-Negoly $\mathrm{S}$, et al. Effect of $16 \%$ carbamide peroxide bleaching gel on enamel and dentin surface micromorphology and roughness of uremic patients: an atomic force microscopic study. Eur J Dent. 2010; 4: 175-82.

16. Featherstone JDB, Ten Cate JM, Shariati M, Arends J. Comparison of artificial caries-like lesions by quantitative microradiography and microhardness profiles. Caries Res. 1983; 17: 385-91.
17. Smidt A, Weller D, Roma I, Gedalia I. Effect of bleaching agents on microhardness and surface morphology of tooth enamel. Am J Dent. 1998; 11: 83-5.

18. Attin T, Schmidlin PR, Wegehaupt F, Wiegand A. Influence of study design on the impact of bleaching agents on dental enamel microhardness: a review. Dent Mater. 2009; 25: 143-57.

19. Mondelli RFL, Gabriel TRCG, Rizzante FAP, Magalhães AC, Bombonatti JFS, Ishikiriama SK. Do different bleaching protocols affect the enamel microhardness? Eur J Dent 2015; 9: 25-30.

20. Tezel H, Ertas OS, Ozata F, Dalgar H, Korkut ZO. Effect of bleaching agents on calcium loss from the enamel surface. Quintessence Int. 2007; 38: 339-47.

21. Cavalli V, Arrais CA, Giannini M, Ambrosano GM. High-concentrated carbamide peroxide bleaching agents effects on enamel surface. J Oral Rehabil. 2004; 31: 155-9.

22. Cochrane NJ, Cai F, Huq NL, Burrow MF, Reynolds EC. New approaches to enhanced remineralization of tooth enamel. J Dent Res. 2010; 89: 1187-97.

23. Titley K, Torneck CD, Smith D. The effect of concentrated hydrogen peroxide solutions on the surface morphology of human tooth enamel. J Endod. 1988; 14: 69-74

24. Ferreira S da S, Araújo JL, Morhy ON, Tapety CM, Youssef MN, Sobral MA. The effect of fluoride therapies on the morphology of bleached human dental enamel. Microsc Res Tech. 2011; 74: 512-6. 